\title{
Seismic Fragility Curves of Industrial Buildings by Using Nonlinear Analysis
}

\author{
Fadzli Mohamed Nazri ${ }^{1, *}$, Syamimi Tahar $^{1}$, Siti Nur Aqilah Saruddin ${ }^{1}$, and Shahiron \\ Shahidan $^{2}$ \\ ${ }^{1}$ School of Civil Engineering, Engineering Campus, Universiti Sains Malaysia, \\ 14300 Nibong Tebal, Penang, Malaysia \\ ${ }^{2}$ Jamilus Research Center-Sustainable Construction, Faculty of Civil and Environmental Engineering, \\ Universiti Tun Hussein Onn Malaysia, 86400, Batu Pahat, Johor, Malaysia
}

\begin{abstract}
This study presents the steel fragility curves and performance curves of industrial buildings of different geometries. The fragility curves were obtained for different building geometries, and the performance curves were developed based on lateral load, which is affected by the geometry of the building. Three records of far-field ground motion were used for incremental dynamic analysis (IDA), and the design lateral loads for pushover analysis (POA). All designs were based on British Standard (BS 5950); however, Eurocode 8 was preferred for seismic consideration in the analysis because BS 5950 does not specify any seismic provision. The five levels of performance stated by FEMA-273, namely, operational phase, immediate occupancy, damage control, life safety, and collapse prevention (CP) were used as main guidelines for evaluating structural performance. For POA, Model 2 had highest base shear, followed by Model 1 and Model 3, even though Model 2 has a smaller structure compared with Model 3. Meanwhile, the fragility curves showed that the probability of reaching or exceeding the CP level of Model 2 is the highest, followed by that of Models 1 and 3 .
\end{abstract}

\section{Introduction}

Structures need to be well designed and constructed to reduce damage. Industrial structures are commonly composed of prefabricated structures or steel because of their lightweight features and the maximum span between columns must not exceed $10 \mathrm{~m}$. Damage on industrialized structures is commonly caused by brace buckling [1], which can be assessed based on the performance level of drift. Drift is commonly used as a damage parameter to predict the performance of industrialized buildings.

Drift has primary effects caused by the movement of structural elements, nonstructural elements, and adjacent structures [2]. Drift can be described by considering the maximum allowable damage state to identify the performance level [3]. The performance level is classified according to FEMA 273 [4] and FEMA-356 [5] guidelines. These guidelines describe four types of performance levels, namely, fully operational (damage is

*Corresponding author: cefmn@usm.my 
negligible and facilities continue their operations), operational (minor damage and minor disruption, facilities continue their operations), life safe (damage is moderate to extensive, lives are slightly at risk), and near collapse (structural collapse is impeded, lives are at risk).

Fragility can be used as a tool for predicting structural and non-structural damage [6]. The fragility curve expresses the probability of a structure exceeding or reaching its damage state [7-13], and allows for estimating the structural damage level for a known ground motion index. The current study has two main objectives: (i) to examine the drift of a structure based on different industrial building designs and (ii) to develop the seismic fragility curve for industrial structures based on different geometries.

\section{Structural geometry}

Three different types of geometry were applied in this study. Geometry is based on the typical types of industrial buildings in Malaysia, as shown in Fig. 1. All models are $6 \mathrm{~m}$ in height with different numbers of bays. Table 1 presents the summary of the industrial building models in this study.

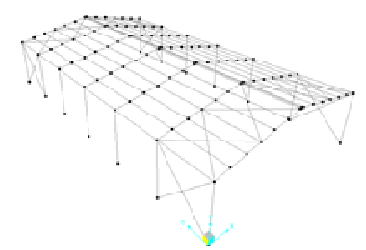

(a) Model 1

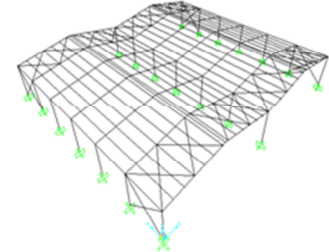

(b) Model 2

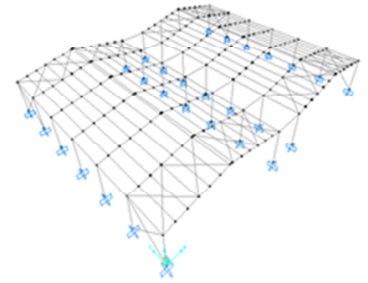

(c) Model 3

Fig. 1. 3D model with different geometry.

Table 1. Summary of industrial building models.

\begin{tabular}{|c|c|c|c|c|c|}
\hline Frame & nb & $\begin{array}{c}\mathbf{L b} \\
{[\mathrm{m}]}\end{array}$ & $\begin{array}{c}\mathbf{L c} \\
{[\mathrm{m}]}\end{array}$ & Beam Section & Column Section \\
\hline 1 & 1 & 6 & 6 & UB $533 \times 210 \times 82$ & UC $356 \times 168 \times 129$ \\
\hline 2 & 2 & 6 & 6 & UB 406x 140x46 & UC $305 \times 305 \times 198$ \\
\hline 3 & 3 & 6 & 6 & UB $356 \times 171 \times 151$ & UB $457 \times 152 \times 60$ \\
\hline
\end{tabular}

The live loads are $1 \mathrm{kN} / \mathrm{m}$ and dead loads are $2 \mathrm{kN} / \mathrm{m}$. The models are assumed suited at soil type A, which is considered stable rock, such as geological formations with least $5 \mathrm{~m}$ of weaker material at the surface. Soil type A was used in this study to avoid soil-structure interaction in the analysis. SAP 2000 was used as the main tool to analyze the two types of practice-oriented methods, namely, pushover analysis (POA) and incremental dynamic analysis (IDA).

Several aspects need to be defined to perform POA, including material information, frame dimension, load patterns, load cases, frame hinge properties, and joint constraint [14]. These aspects must be assigned on the model of the existing industrial building for the analysis. All connections must be assigned correctly to avoid error. In this study, models were introduced in uniform distribution. 
The selection of ground motion records is important for IDA. An appropriate number of recordings is a significant concern [15-16]. However, most codes [5, 18-19] recommend a minimum of three or seven sets of ground motion records. For this study, three sets of ground motions were used and selected from the PEER NGA website (Table 2).

Table 2. Selected ground motions records

\begin{tabular}{|c|c|c|c|}
\hline Name Record & Earthquake Location & Year & Magnitude \\
\hline Chichi & Chichi, Taiwan & 1975 & 7.8 \\
\hline Kobe & Kobe, Japan & 1975 & 6.8 \\
\hline Tehri & Tehri, India & 1979 & 6.8 \\
\hline
\end{tabular}

Far-field (FF) ground motions were chosen based on the following criteria: (i) JoynerBoore distance is more than $20 \mathrm{~km}$ and (ii) magnitude ranges from 7 to 8 . These ground motions were then scaled to elastic response spectra. The elastic response spectra were developed from $0 \mathrm{~g}$ to $6 \mathrm{~g}$ (an increment of $2 \mathrm{~g}$ ).

To develop a fragility curve, the IDA curve with the displacement or drift of a structure must be obtained. The fragility curve can be plotted using the suggested limit condition in PGA-drift format form [20]. Equation (1), as suggested by Ibrahim and El-Shami [6] was used in this study to develop the fragility curve.

$$
P[\mathrm{D} / \mathrm{PGA}]=\Phi((\ln (\mathrm{PGA})-\mu) / \sigma)
$$

where ;

$$
\begin{aligned}
& \mathrm{D} \quad=\text { damage } \\
& \mathrm{PGA}=\text { Peak Ground Acceleration } \\
& \Phi \quad=\text { standard normal cumulative distribution } \\
& \mu \quad=\text { mean } \\
& \sigma \quad=\text { standard deviation of the natural logarithm of PGA }
\end{aligned}
$$

\section{Results and discussion}

The results obtained from POA and IDA was evaluated by comparing them with the limit state based on PBSD. Five limit states were used, namely, operational phase (OP) with $0.5 \%$ drift, immediate occupancy (IO) with $1.0 \%$ drift, damage control (DC) with $1.5 \%$ drift, life safety (LS) with $2.0 \%$ drift, and collapse prevention (CP) with more than $2.5 \%$ drift.

\subsection{Seismic performance}

A base shear versus drift graph can be plotted from the POA results. This performance curve can describe the maximum allowable damage condition for a known seismic hazard. Fig. 2 shows the performance curves for the three models.

Based on Fig. 3, at $0.5 \%$ drift, the base shears of Model 2 and 3 were similar, but a small difference was found between the base shears of Model 1 and Model 2 (i.e., 14\%). At $1.1 \%$ drift, the performance curves of Model 2 and 3 start to diverge. At the CP level, a $16 \%$ difference between Model 1 and Model 2 was observed at 2.5\% drift. Meanwhile, the difference between Model 2 and Model 3 at 2.5\% drift was approximately 21\%. Although Model 3 is larger, Model 2 reaches a base shear that is greater than that of Model 3. This difference is probably because the structure of Model 3 is composed of smaller members. The column on Model 3 cannot resist the lateral load exerted on the structure, resulting in a low ability to resist the lateral load applied. 


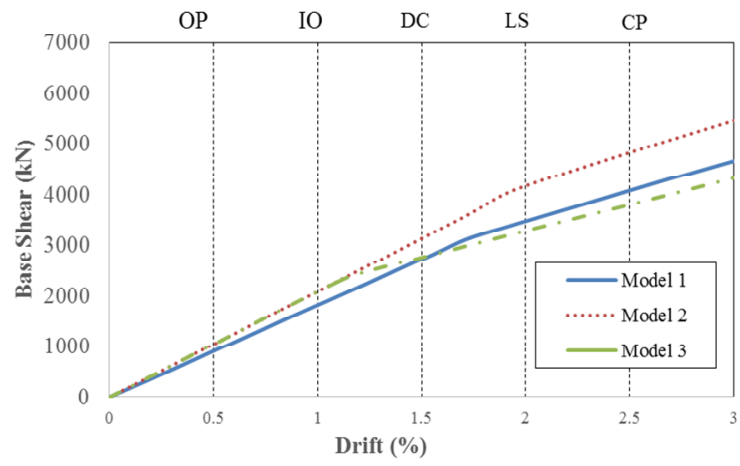

Fig. 2. Seismic performance.

\subsection{Hinge deformation}

Figure 3 shows the hinge deformation for all models that based on the IDA. The most common failure that occurs in Model 1 and Model 2 is at the column member. For Model 3, failure occurs at the truss and column section. From the hinge deformation result, Model 3 has the worst damage because Model 3 reaches Level 7. The most severe damage occurs at the column, which may be because the structure uses small sections for columns (i.e., UB547×152×60) compared with other models using UC section. Model 2 has a greater damage level than Model 1 because it reached level 5, which is the collapse level. Collapse may occur because of the greater size of the structure of Model 2 than Model 1. In addition, the damage may be due to connection failures, given that Model 2 has no detailed design.
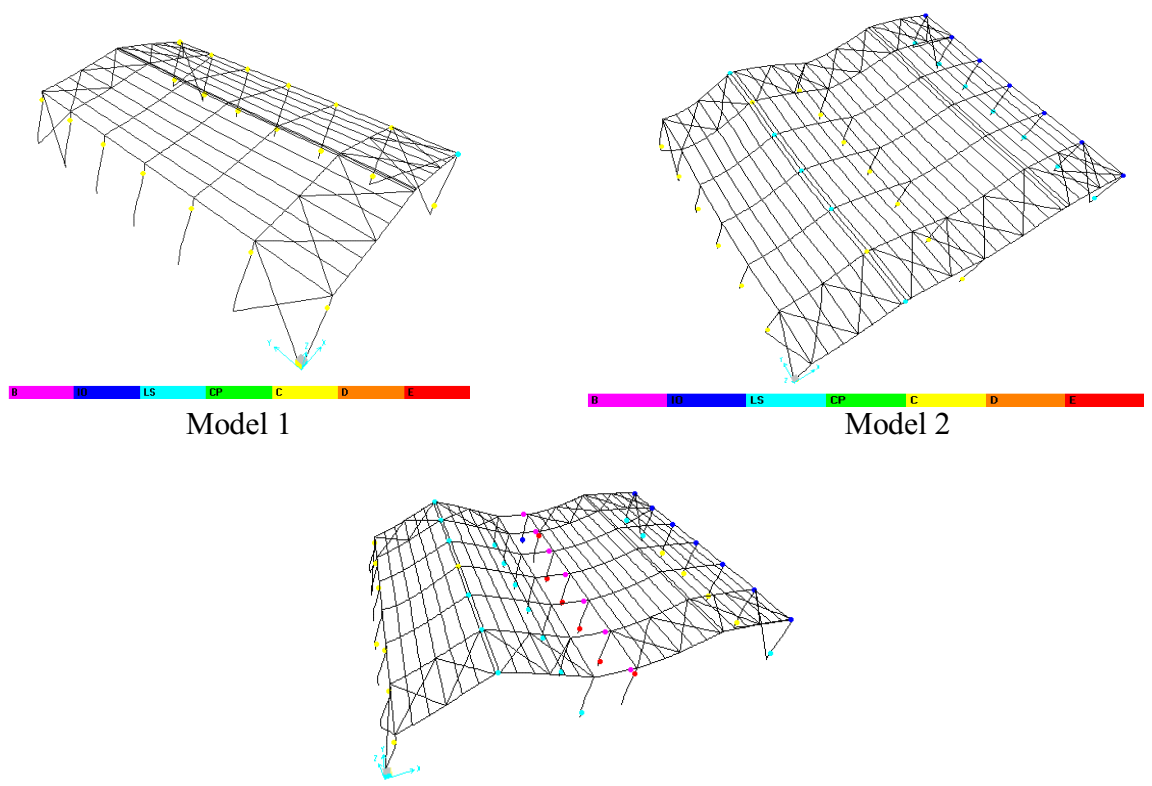

Fig. 3. Hinge deformation

$$
\text { Model } 3
$$




\subsection{IDA}

IDA was conducted under each ground motion and the scaling PGA increased every $2 \mathrm{~g}$ until reaching $6 \mathrm{~g}$. Normally, the analysis would be stopped when PGA reaches $6 \mathrm{~g}$ because structures are commonly unstable at $6 \mathrm{~g}$. Every structure has different behavior toward ground motion, and thus the ground motion records have different patterns of IDA curves. An IDA curve shows the relationship between drift and PGA. In this study, drift was only emphasized until 3\% to develop the seismic fragility curve; $3 \%$ is the maximum drift limit according to FEMA-273. The mean drift was calculated for every PGA to present the average of the IDA curves and was compared with the limit state, as shown in Fig. 4.

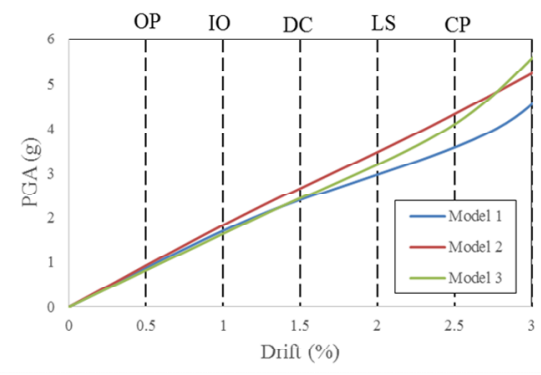

Fig. 4. Mean IDA.

Based on the observation at the CP levels, Model 2 has a better performance than Model 1 and 3, because the members of Model 2 are strong enough to for the ground motion. The larger structural members of Model 2 endow stability when ground motion occurs. The mean difference between Model 2 and 3 is only about 5\%. Although Model 3 is larger than Model 2, Model 3 cannot resist the load applied on the structure because the compression members of Model 3 are smaller (UB section). If Model 3 were designed with a UC section at the compression member, then Model 3 would have inferior performance to Model 2. In terms of structural size (whole), Model 3 is the largest, followed by Model 2 and Model 1. Among the models, Model 1 has the lowest performance. The mean difference between Model 1 and Model 2 is about 17\%., which might be due to the design and size of the structure. Thus, Model 1 will collapse before Model 2 and Model 3.

\subsection{Fragility curve}

Two parameters, namely, mean and standard deviation, are needed to develop a fragility curve. The mean and standard deviation of PGA were calculated for every point in the IDA curve, which were across the vertical gridlines of limit state at drifts. The calculated parameters are provided in Table 3. The fragility curves were developed using (1). All seismic fragilities were represented in the damage probability curves, as shown in Fig. 5.

Table 3. Parameters of log-normaldistribution of the models.

\begin{tabular}{|c|c|c|c|c|c|c|c|c|c|c|}
\hline \multirow{2}{*}{$\begin{array}{c}\text { Mo } \\
\text { del }\end{array}$} & \multicolumn{2}{|c|}{ OP } & \multicolumn{2}{c|}{ IO } & \multicolumn{2}{c|}{ DC } & \multicolumn{2}{|c|}{ LS } & \multicolumn{2}{c|}{ CP } \\
\hline 1 & -0.009 & 0.700 & 0.677 & 0.688 & 0.689 & $\begin{array}{c}0.20 \\
1\end{array}$ & 0.938 & 0.253 & 1.136 & $\begin{array}{c}0.33 \\
4\end{array}$ \\
\hline 2 & -1.332 & 1.372 & 0.673 & 0.871 & $\begin{array}{c}0.610 \\
9\end{array}$ & $\begin{array}{c}0.07 \\
45\end{array}$ & 0.870 & $\begin{array}{c}0.030 \\
4\end{array}$ & 1.201 & $\begin{array}{c}0.13 \\
1\end{array}$ \\
\hline 3 & -0.041 & 0.102 & 0.607 & 0.91 & 0.837 & $\begin{array}{c}0.36 \\
1\end{array}$ & 1.256 & 0.110 & 1.512 & $\begin{array}{c}0.12 \\
1\end{array}$ \\
\hline
\end{tabular}




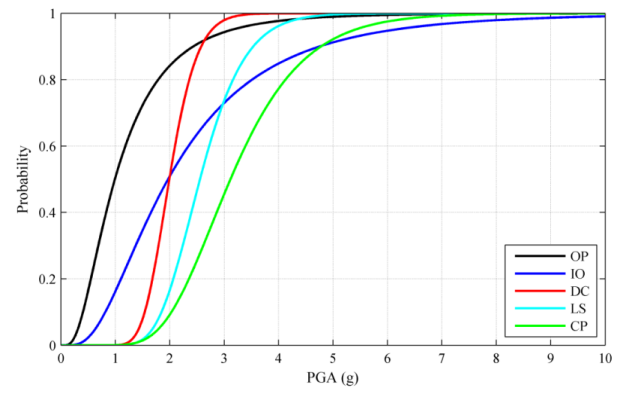

(a) Model 1

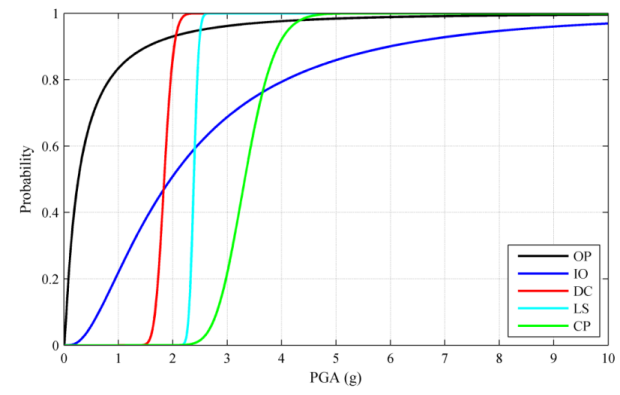

(b) Model 2

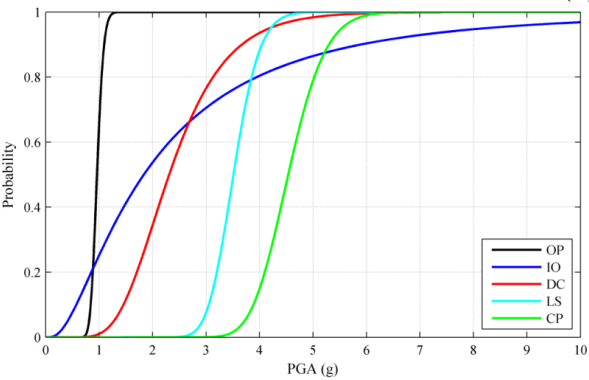

(c) Model 3

Fig. 5. Seismic fragility curves

As shown in Fig. 4(a), at FF ground motion of $1 \mathrm{~g}$, the probabilities of reaching or exceeding the OP and IO levels are $79 \%$ and $26 \%$, respectively. At a ground motion of $5 \mathrm{~g}$, the probabilities of reaching or exceeding the CP and IO levels are approximately $92 \%$ and $90 \%$, respectively, and the probabilities of exceeding or reaching the OP, LS, and DC levels are almost $100 \%$. The following observations were noticed for Model 2 (Fig. 4(b)): when a PGA of $1 \mathrm{~g}$ was exerted, the probabilities of reaching OP and IO levels were $84 \%$ and $22 \%$, respectively. When PGA was $5 \mathrm{~g}$, the probability of reaching the DC, LS, and CP levels were $100 \%$. The probabilities of exceeding or reaching the OP and IO levels were $98 \%$ and $90 \%$, respectively. Fig 4(c) shows the fragility curve of Model 3. At a PGA of $1 \mathrm{~g}$, the probabilities of exceeding or reaching the OP and IO levels are $60 \%$ and $25 \%$, respectively. At a strong ground motion of $5 \mathrm{~g}$, the probabilities of exceeding the OP, IO, DC, LS, and CP levels are $100 \%, 86 \%, 98 \%, 100 \%$, and $78 \%$, respectively.

\section{Conclusions}

This study develops the fragility curve of industrial buildings based on the practiceoriented methods, namely, POA and IDA. The models were designed based on BS 5950; however, they were analyzed according to Eurocode 8 because BS 5950 does not specify any seismic provision. For the analysis, SAP 2000 software was used as the main tool for analyzing the structure under static load (lateral load) and dynamic load (ground motion). Three sets of ground motion records around Asia were chosen, which were classified as FF. The drift of the structure from POA and IDA were investigated. The following conclusions can be drawn from this study.

i) The performance curves were developed using SAP 2000 software. Lateral load exerted on the structure varies depending on the structure. The structure with a greater mass can resist higher base forces. However, the drift of the structure also depends on the design of the industrial building. For instance, although Model 3 has a larger surface area than Model 2, Model 3 collapses 21\% faster than Model 2. Although Model 3 is larger, 
Model 2 reaches a base shear that is greater than Model 3. This result is most probably because Model 3 consists of smaller structural members, and the strength of Model cannot resist the load applied to the structure. The different analyses provided different drifts, even for the same model.

ii) The fragility curves were developed for different types of geometry. The fragility curves were analyzed based on five limit states, namely, OP, IO, DC, LS, and CP. By considering the limit states, designers can predict the damage level and possible location of hinge deformation. Comparison of the fragility curves of the three models show that Model 2 has the highest probability of reaching OP and CP levels.

This research was supported by Ministry of Higher Education under the Fundamental Research Grant Scheme (6071321).

\section{References}

[1] K. Ozakgul, O. Caglayan and O. Tezer, Investigation of buckled brace system of an existing industrial building, Engineering Failure Analysis, 18, 455-463, (2011)

[2] G.R. Searer, and S. A. Freeman, Design drift requirement for long period structures, Proc. of the 13th World Conf. on Earthquake Engineering, 3292, (2004)

[3] A. Hokmabadi, B. Fatahi, and B. Samali, Recording inter-storey drifts of structures in time-history approach for seismic design of building frames, Australian J. of Structural Engineering, 13, 175, (2012)

[4] FEMA-273, 273: NEHRP Guidelines for the seismic rehabilitation of buildings, Federal Emergency Management Agency, Washington, D.C., United States, (1997)

[5] FEMA-356, Prestandard and commentary for the seismic rehabilitation of buildings: FEMA-356, Federal Emergency Management Agency, Washington, D.C., United States, (2000)

[6] Y.E. Ibrahim, and M. M. El-Shami, Seismic fragility curve for mid-rise reinforced concrete frames in kingdom of Saudi Arabia, The IES Journal Part A: Civil and Structural Engineering, 4(4), 213-223, (2011)

[7] A. Réveillère, P. Gehl, D. Seyedi, and H. Modaressi, Development of seismic fragility curves for mainshock-damaged reinforced-concrete structures, in Proc. of the 15th World Conf. on Earthquake Engineering, Lisboa, Portugal, 999, (2012)

[8] E.N. Farsangi, F.H. Rezvani, M. Talebi, and S. A. Hashemi, Seismic risk analysis of steel-mrfs by means of fragility curves in high seismic zones, Advances in Structural Engineering, 17, 1227-1240, (2014)

[9] C.R. Kumar, K.B. Narayan, and D.V. Reddy, Probabilstic seismic risk evaluation of rc buildings, Int. J. of Research in Engineering and Technology, 3, 484-495, (2014)

[10] J. Lee, S. Han, and J. Kim, Seismic performance evaluation of apartment buildings with central core, Int. J. of High-Rise Buildings, 3(1), 9-19, (2014)

[11] V. Silva, H. Crowley, H. Varum, R. Pinho, and R. Sousa, Evaluation of analytical methodologies used to derive vulnerability functions, Earthquake Engineering \& Structural Dynamics, 43, 181-204, (2014)

[12] R. Ahmadi, R. Mulyani, F.M. Nazri, K. Pilakoutas and I. Hajirasouliha, Seismic vulnerability assessment of an industrial building in Peninsular Malaysia, 5th Brunei Int. Conf. on Engineering and Technology (BICET 2014), Bandar Seri Begawan, 1-6, (2014)

[13] C. Casotto, V. Silva, H. Crowley, R. Nascimbene, and R. Pinho, Seismic fragility of Italian RC precast industrial structures. Engineering Structures, 94, 122-136, (2015) 
[14] F.M. Nazri, and Y.K. Pang, Seismic performance of moment resisting steel frame subjected to earthquake excitations, Frontiers of Structural and Civil Engineering, 8, 19-25, (2014)

[15] B.Ö. Ay, and S. Akkar, A procedure on ground motion selection and scaling for nonlinear response of simple structural systems, Earthquake Engineering and Structural Dynamics, 41, 1693-1707, (2012)

[16] L.H. Najafi, and M. Tehranizadeh, Ground motion selection and scaling in practice. Periodica Polytechnica Civil Engineering, 59(2), 233 - 248, (2015)

[17] IBC, International Code Council Inc., International Building Code, Falls Church, VA, USA (2000)

[18] Eurocode 8, Design provisions for earthquake resistance of structures: Part 1-1, General rules - seismic actions and general requirements for structures, BS EN: 19981-1: 2004, British Standards Institution, London, United Kingdom, (2014)

[19] Q. Xue, C.W. Wu, C.C. Chen, and K.C. Chen, The draft code for performance-based seismic design of buildings in Taiwan, Engineering Structures, 30, 1535-1547, (2008) 